\title{
Prevalence of intestinal parasites in relation to CD4 counts and anaemia among HIV- infected patients in Benin City, Edo State, Nigeria
}

\author{
FREDERICK O. AKINBO ${ }^{1,2^{*}}$, CHRISTOPHER E. OKAKA ${ }^{2}$, and RICHARD OMOREGIE ${ }^{3}$ \\ ${ }^{1}$ Department of Pathology, University of Benin Teaching Hospital, PMB 1111, Benin City, Nigeria \\ ${ }^{2}$ Department of Animal and Environmental Biology, University of Benin, Benin City, Nigeria \\ ${ }^{3}$ School of Medical Laboratory Sciences, University of Benin Teaching Hospital, Benin City, Nigeria
}

\begin{abstract}
Parasitic infections continue to take their toll on HIV positive patients by influencing the blood qualitatively and quantitatively. The objective of this study was to determine the prevalence of intestinal parasitic infections in relation to anaemia and CD4 counts among HIV-infected patients in Benin City, Nigeria. Using a serial sampling method, a total of $2000 \mathrm{HIV}$-infected patients were recruited on their first visit prior to highly active anti-retroviral therapy (HAART) at the University of Benin Teaching Hospital from August 2007 to August 2009. Stool and blood samples were collected from each patient. The stool samples were processed using the modified Ziehl-Neelsen staining technique to microscopically identify the oocysts of Cryptosporidium species, Isospora belli, Cyclospora species and spores of Microsporidium species while saline and iodine preparations were used for identifying the ova, cysts and parasites of Ascaris lumbricoides, hookworm, Taenia spp and other parasites. The blood specimens were equally analyzed using the flow cytometry for $\mathrm{CD} 4^{+} \mathrm{T}-$ lymphocyte count and autoanalyzer - sysmex $\mathrm{kx}-21$ for haemoglobin concentration. The overall prevalence of anaemia was $93.3 \%$ while $18 \%$ had parasitic infections. There was a significant relationship between CD4 count $<200$ cells/ $\mu \mathrm{L}$ and anaemia $(P<0.0001)$. Cryptosporidium species $(P=0.005)$, A. lumbricoides $(P=0.035)$, hookworm and Taenia species $(P=0.014)$ were associated with anaemia. Anaemia was associated with CD4 count while Cryptosporidium species, Ascaris lumbricoides, hookworm and Taenia species were the intestinal parasitic agents associated with anaemia. In conclusion the prevalence of anaemia in HIV-infected patients is high low CD4 count is a significant risk factor of acquiring anaemia. Except for isosporiasis, cryptosporidiosis, A. lumbricoides, hookworm and Taenia species in HIV infected individuals are parasitic agents associated with anaemia. Routine screening for intestinal parasites and holistic management of anaemia is advocated.
\end{abstract}

Keywords: intestinal parasites, anaemia, CD4 counts, HIV/AIDS, Nigeria

\section{Introduction}

Parasitic infections continue to take their toll on HIV-infected individuals by negatively influencing the blood qualitatively and quantitatively. Anaemia, which can be mild to severe, acute or chronic, is one of the multitudes of complications associated with parasitic infections (Agiomea, 2003). Anaemia is a frequent complication of HIV/AIDS which contributes to reduced quality of life and increased morbidity and mortality (Akinbo et al., 2009a). The relationship between parasitic infection and anaemia is a pathogeno-physiologic type (Stephenson et al., 1985) where it is recognized that certain factors play important roles. These include the strain and number of the parasites, the size and site, metabolic processes of the parasite, age and level of immunity at the time of infestation, presence of co-existing diseases or

\footnotetext{
* Correspondence: Frederick O. Akinbo; E-mail: fgbengang@yahoo.com
} 
conditions which reduce immune responses, malnutrition, and the life style of the person infested (Cheesebrough, 1999).

In Africa, intestinal parasitic infections are among the major causes of anaemia due to generally poor standard of living among the populace (Latham et al., 1977; Mupfasoni et al., 2009). Previous studies have revealed that HIV patients with malaria infection are more likely to develop anaemia, while a CD4 $+\mathrm{T}$ cell count of $<200$ cells $/ \mu \mathrm{L}$ was associated with an increased risk of parasitic infection among HIV-infected patients (Akinbo et al., 2009b). There is paucity of information as regards an association of anaemia and CD4 count among HIV-positive subjects that are infected with parasitic infections. Against this background, this was study carried out to determine the prevalence of intestinal parasitic infections in relation to anaemia and CD4 counts among HIV-infected patients in Benin City, Nigeria.

\section{Materials and Methods}

\section{Study area and population}

The study was carried out in the University of Benin Teaching Hospital, Benin City, Nigeria. It is located in the South-South geopolitical zone of Nigeria. It serves as a referral hospital to about 6-10 States in Nigeria. It is a centre for Institute of Human Virology, Nigeria and President's Emergency Plan for AIDS Relief (PEPFAR) HIV/AIDS interventions in the zone.

HIV- positive patients attending HIV clinic at the University of Benin Teaching Hospital, Benin City, Nigeria from August 2007 to August 2009, were recruited for this study. Patients on HAART, antiparasitic agents and AIDS defining conditions were excluded from the study. The study participants were selected by serial sampling technique.

\section{Specimen collection and processing}

Stool and $5 \mathrm{ml}$ of blood specimens were collected from each patient. The stool specimens were collected in clean wide-mouthed container while venous blood specimens were collected through the use of a dry, sterile syringe and needle, the blood was withdrawn, with minimum stasis from a suitable vein in the arm. The blood was slowly dispensed into ethylene diamine tetra-acetic acid (EDTA) container and mixed well (Baker et al., 2001).

Freshly voided stool specimens were processed using formol-ether concentration method and examined microscopically for intestinal parasites as previously described (Cheesbrough, 1999). Part of the stool specimen was preserved in 10\% formal-saline. From this, a concentrated smear was made, fixed with methanol and stained by a modified Ziehl-Neelsen stain. This was used to detect oocyst of Cryptosporidium species, Isospora belli, Cyclospora species and spores of Microsporidium species.

The blood specimens were used for $\mathrm{CD}^{+}$T-lymphocyte count and haemoglobin concentration. The $\mathrm{CD}^{+}$count was determined by flow cytometry (Partec, Gmbh, Germany) while haemoglobin concentration was determined using an autoanalyser-sysmex kx-21 (Sysmex Corporation, Kohe, Japan). Anaemia was defined according to WHO criteria (Bentler \& Wealen, 2006). For males, this was haemoglobin concentration $<13 \mathrm{~g} / \mathrm{dl}$ and for females it was $<12 \mathrm{~g} / \mathrm{dl}$.

\section{Data analysis}


Data were analyzed using Chi-square $\left(\mathrm{X}^{2}\right)$ test (for differences in prevalence) and odd ratio analysis (to assess risk factors). The statistical software INSTAT ${ }^{\circledR}$ was used for the analysis.

\section{Ethical consideration}

The Ethical Committee of the University of Benin Teaching Hospital, Benin City, Nigeria, approved the protocol of this study. Verbal informed consent was obtained from every patients enrolled in this study.

\section{Results}

A total of 2000 patients were recruited. They consisted of 668 (33.4\%) males and 1332 (66.6\%) of females with age ranging from $21-70 y e a r s ~(37.06 \pm 9.19)$. The majority $(1866 ; 93: 30 \%)$ of $\mathrm{HIV}$ patients had anaemia while only a few (18.0\%; N=360) had parasitic infections. CD4 count $<200$ cells $/ \mu \mathrm{L}$ was a significant risk factor for acquiring anaemia $(\mathrm{OR}=42.65,95 \% \mathrm{CI}=2.64,688.00$; $P<0.0001$ ) (Table 1).

Table 1: Relationship between anaemia, parasitic infections and CD4 counts

\begin{tabular}{|c|c|c|c|c|c|c|}
\hline Characteristics & & $\begin{array}{l}\text { CD4 C } \\
\text { (Cells/ul) } \\
<200(\%)\end{array}$ & $\geq 200(\%)$ & OR & $95 \% \mathrm{CI}$ & P-value \\
\hline Anaemia & Yes & $255(100)$ & $1611(92.3)$ & 42.65 & $2.64,5.88 .0$ & \\
\hline & No & $0(0)$ & $134(7.68)$ & 0.02 & $0.0,0.38$ & $<0.0001$ \\
\hline Infection with & Yes & $79(100)$ & $233(82.92)$ & 33.03 & $2.01,542.2$ & \\
\hline anaemia & No & $0(0.0)$ & $48(17.08)$ & 0.03 & $0.00,0.50$ & 0.0002 \\
\hline
\end{tabular}

Isospora belli and Cryptosporidium species were the only intestinal parasite associated with CD4 count $<200$ cells $/ \mu \mathrm{L}$ (Table 2). Cryptosporidium species, Ascaris lumbricoides, hookworm and Taenia species were the intestinal parasites associated with anaemia (Table 3). The prevalence of parasites were Entamoeba histolytica (3.33\%), Giardia intestinalis (0.56\%), Isospora belli (7.78\%), Cryptosporidium species (22.22\%), Ascaris lumbricoides (33.06\%), Hookworm (20.56\%), Strongyloides stercoralis (6.39\%), Trichuris trichuria (5.00\%) and Taenia species $(1.11 \%)$.

Table 2: Effect of CD4 count on the prevalence of parasitic agents

\begin{tabular}{llllll}
\hline Parasitic Agents & \multicolumn{2}{l}{ CD4 count $(\mathrm{cells} / \boldsymbol{\mu L})$} & $\mathbf{9 5} \% \mathbf{C I}$ & P-value \\
& $\begin{array}{l}<\mathbf{2 0 0} \\
\mathrm{n}=255^{*}\end{array}$ & $\begin{array}{l}\mathbf{2 0 0} \\
\mathrm{n}=1745\end{array}$ & $\mathrm{OR}$ & & \\
\hline Entamoeba histolytica & 0 & 12 & 0.271 & $0.016,4.601$ & 0.371 \\
Giardia intestinalis & 0 & 2 & 1.365 & $0.065,28.530$ & 0.589 \\
Isospora belli & 11 & 16 & 4.872 & $2.234,10.622$ & $<0.0001$ \\
Cryptosporidium species & 59 & 21 & 24.712 & $14.698,41.551$ & $<0.0001$ \\
Ascaris lumbricoides & 16 & 103 & 1.067 & $0.619,1.839$ & 0.926 \\
Hookworm & 9 & 65 & 0.946 & $0.465,1.923$ & 0.877 \\
Strongyloides stercoralis & 3 & 20 & 1.027 & $0.303,3.481$ & 0.966
\end{tabular}




\begin{tabular}{|c|c|c|c|c|c|}
\hline Trichuris trichiura & 4 & 1.838 & & 5.583 & 457 \\
\hline Taenia species & 1 & 3.431 & & 37.998 & 839 \\
\hline $\begin{array}{l}\text { Key: }{ }^{*} \text { number of patients } \\
\text { and } 3 \text { are the number of } p\end{array}$ & $\begin{array}{l}\text { h CD4<200 cell } \\
\text { nts infected wi }\end{array}$ & $\begin{array}{l}\mu l ; * \text { number of } \\
\text { a particular para }\end{array}$ & $\begin{array}{l}\text { atients } \\
\text { sitic ager }\end{array}$ & CD4 $\geq 200$ cells/ & igures in \\
\hline Parasite & $\begin{array}{l}\text { No. with } \\
\text { anaemia (\%) }\end{array}$ & $\begin{array}{l}\text { No. without } \\
\text { anaemia (\%) }\end{array}$ & OR & $95 \%$ CI & P-value \\
\hline & $\mathrm{N}=1866$ & $\mathrm{~N}=143$ & & & \\
\hline Entamoeba histolytica & 12 & 0 & 1.813 & $0.107,30.811$ & 0.725 \\
\hline Giardia intestinalis & 2 & 0 & 0.361 & $0.017,7.557$ & 0.705 \\
\hline Isospora belli & 28 & 0 & 4.170 & $0.253,63.724$ & 0.295 \\
\hline Cryptosporidium spp. & 80 & 0 & 12.121 & $0.747,196.680$ & 0.027 \\
\hline Ascaris_lumbricoides & 119 & 0 & 18.395 & $1.137,297.65$ & 0.005 \\
\hline Hookworm & 74 & 0 & 11.180 & $0.689,181.53$ & 0.035 \\
\hline Strongyloides stercoralis & 23 & 0 & 3.429 & $0.207,56.803$ & 0.383 \\
\hline Trichuris trichiura & 18 & 0 & 2.692 & $0.161,44.948$ & 0.504 \\
\hline Taenia species & 2 & 0 & 0.071 & $0.010,0.507$ & 0.014 \\
\hline
\end{tabular}

\section{Discussion}

Anaemia is one of the haematological complications seen in HIV-positive patients (Moyle, 2002) and is a significant predictor of progression to AIDS or death (Odunukwe et al., 2005). Parasitic infections are known to cause anaemia among non-HIV subjects (Oguntibeju, 2003; Agbolade et al., 2009) as well as among HIV patients (Akinbo et al., 2009a). As HIV infection progresses to AIDS, a number of opportunistic infections and other sequela occur. Parasitic infections (especially intestinal) and anaemia are among the morbidities seen in HIV patients (Oguntibeju, 2006; Zelalem et al., 2008; Akinbo et al., 2009a, 2010).

The prevalence of HIV-positive patients who had intestinal parasitic infections in this study was lower than the previous reports by Oguntibeju (2006). The difference is due to type of patients used. Oguntibeju (2006) used both HIV-positive and AIDS patients, while only HIVpositive patients were used in this study. Anaemia prevalence in this study was higher than previous reports in HIV patients (Akinbo et al., 2009a; Omoregie \& Eghafona, 2009; Omoregie et al., 2009). The cause of anaemia in HIV-positive patients is multi-factorial and includes infections, neoplasm, dietary deficiencies, blood loss, medications and antibodies to antiretroviral agents (Moyle, 2002; Omoregie et al., 2008). Also, bone marrow suppression, especially the erythroid lines, by the AIDS virus is known to result in anaemia (Odunukwe et al., 2005). Indeed, CD4 count of $<200$ cells $/ \mu \mathrm{L}$ was a significant risk factor for anaemia in this 
study. This agrees with a previous report by Curkendall et al. (2006). However, according to Omoregie et al. (2009) the relationship between CD4 counts and anaemia depends of the cut-off values for CD4.

In a similar vein, intestinal parasitic infection among HIV patients with anaemia is significantly associated with CD4 count $<200$ cells/ $\mu \mathrm{L}$. Intestinal parasitic infections contribute to the anaemia seen in HIV-positive patients, especially, when the CD4 count is $<200$ cells/ $\mu \mathrm{L}$. This is important as CD4 count <200cells/ $\mu \mathrm{L}$ is believed to be associated with disease progression and opportunistic infections (Oguntibeju et al., 2006). This may explain the association between CD4 count and parasitic infections among HIV patients with anaemia.

The parasites observed in this study had previously been noted in HIV patients (Hailermariam et al., 2004; Oguntibeju, 2006; Kwitshana et al., 2008). I. belli and Cryptosporidium species were the only parasites associated with CD4 count $<200$ cells/ $\mu \mathrm{L}$. This is in agreement with other recent observations (Akinbo et al., 2009b; Akinbo et al., 2010). Isosporiasis and cryptosporidiosis are opportunistic infections (Zelelam et al., 2008; Guptal et al., 2008). In relation to anaemia, Cryptosporidium species, A. lumbricoides, hookworm and Taenia species were the only parasites that were significantly associated with anaemia. A. lumbricoides, hookworm and Taenia species are known to cause anaemia among non-HIV subjects (Oguntibeju, 2003; Vuylsteke et al., 2004; Agbolade et al., 2009). To our knowledge, this is the first report associating cryptosporidiosis with anaemia. Cryptosporidiosis is usually associated with diarrhea and weight loss (Kulkarni et al., 2009). This will require further investigation especially the mechanism by which Cryptosporidium species cause anaemia. It is important that HIV-positive patients be screened for intestinal parasitic infections so that there can be a holistic management of anaemia when indicated, in order to improve quality of life of HIV-positive patients.

In conclusion the prevalence of anaemia in HIV-infected patients is high low CD4 count is a significant risk factor of acquiring anaemia. Isosporiasis and cryptosporidiosis were associated with immunodeficiency while Cryptosporidium species, Ascaris lumbricoides and hookworm were the intestinal parasitic agents associated with anaemia

\section{Competing interests}

The authors declare that they have no competing interests.

\section{Acknowledgements}

We acknowledge with thanks the Management of University of Benin Teaching Hospital for permission to carry out this study.

\section{References}

Agiomea, K. (2003) Anaesthetic considerations in patients with parasitic diseases and anaemia: http://www.nda.ox.ac.uk/wfsa/al/htl/papers/pap021.html;1-8 
Agbolade, O.M., Abimbola, W.A., Bolarinwa, O.I., Akinboye, D.O. \& Ogunkolo, O.F. (2009) Parasitic infestations, anaemia and blood glucose level in out-patients of a secondary health centre in south-western Nigeria. World Journal of Medical Sciences 4, 147-150.

Akinbo, F.O., Okaka, C.E. \& Machado, R.L.D. (2009a) Isosporiasis in HIV/AIDS patient in Edo State, Nigeria. Malaysian Journal of Medical Sciences 16, 43-46.

Akinbo, F.O., Okaka, C.E., Omoregie, R. \& Igbinumwen, O. (2009b) Prevalence of malaria and anaemia among HIV-infected patient in B/C Nigeria. New Zealand Journal of Medical Laboratory Sciences 63, 78-80.

Akinbo, F.O., Okaka, C.E., Machado, R.L.D., Omoregie, R. \& Onunu, A.N. (2010) Cryptosporidiosis among HIV-infected patients with diarrhoea in Edo State, Midwest Nigeria. Malaysian Journal of Microbiology 6, 99-101.

Baker, F.J., Silverton, R.E. \& Pallister, C.J. (2001) Introduction to Medical Laboratory Technology. $7^{\text {th }}$ Ed. Bounty Press Limited, Ibadan, Nigeria. pp 348.

Bentler, E. \& Wealen, J. (2006) The definition of anaemia: what is the lower limit of normal blood haemoglobin concentration? Blood 107, 1747-1750

Cheesbrough, M. (1999) Parasitological Tests. Cambridge University Press.

Curkendall, S.M., Richardson, J.T., Emons, M.F., Fisher, A.E. \& Everhard, F. (2007) Incidence of anaemia among HIV-infected patients treated with highly active antiretroviral therapy. HIV Medicine 8, 483-490.

Guptal, S., Narang, S., Nunavath, V. \& Single, S. (2008) Chronic diarrhea in HIV patients: prevalence of coccidian parasites. Indian Journal of Medical Microbiology 26, 172-175.

Kulkarni, S.V., Kasion, R., Sane, S.S., Padmawar, P.S., Kale, V.A., Thakar, M.R., Mehendala, S.M. \& Risbod, A.R. (2009) Opportunistic parasitic infections in HIV/AIDS patients presenting with diarrhea by the level of immonosuppression. Indian Journal of Medical Research130, 63-66

Kwitshana, Z.L., Dhansay, J.M. \& Tsoka, M.L.H. (2008) Intestinal parasitic infections in adult patients in Kwazulu-Natal. South African Medical Journal 98, 709-711.

Latham, M.C., Brooks, R.M. \& Basta, S.S. (1977) The relationship of nutrition and health to worker productivity in Kenya. World Bank Study of the substitution of labour and equipment in civil construction. IBRD Technical Memorandum. Washington D.C.

Moyle, G. (2002) Anaemia in persons with HIV infection: prognostic marker and contributor to morbidity. AIDS Reviews 4,13-18.

Mupfasoni, D., Karibushi, B., Koukounari, A., Ruberanziza, E., Kaberuka, T., Kramer, M.H., Mukabayire, O., Kabera, M., Nizeyimana, V., Deville, M.A., Ruxin, J., Webster, J.P. \& Femick, A. (2007) Polyparasite helminth infections and their association to anaemia and undernutrition in Northern Rwanda. Plos Neglected Tropical Diseases 3(9): e517.

Odunukwe, N., Idigbe, O., Kanki, P., Adewale, T., Onwujekwe, D., Audu, R. \& Onyewuche, J. (2005) Haematological and biochemical response to treatment of HIV-1 infection with a combination of nevirapine stavudine + lamivudine in Lagos Nigeria. Turkish Journal of Haematology 22, 125-131.

Oguntibeju, O.O. (2003) Parasitic infections and anaemia: the prevalence in a rural hospital setting. Journal of Biomedical \& Laboratory Sciences15, 12-15. 
Oguntibeju, O.O. (2006) Prevalence of intestinal parasites in HIV-positive/AIDS patients. Malaysian Journal of Medical Sciences 13, 68-73.

Oguntibeju, O.O., Vanden-Heever, W.M.J. \& van-Schankwyk, F.E. (2006) Effect of liquid nutritional supplement on viral load and haematological parameters in HIVpositive/AIDS patients. British Journal of Biomedical Sciences 63,134-139.

Omoregie, R. \& Eghafona, N.O. (2009) Effect of urinary tract infections on the prevalence of anaemia among HIV patients in Benin City, Nigeria. New Zealand Journal of Medical Laboratory Sciences 63, 44-46.

Omoregie, R., Egbeobauwaye, A., Ogefere, H., Omokaro, E.U. \& Ehen, C.C. (2008) Prevalence of antibodies to HAART agents among HIV patient in Benin City, Nigeria. African Journal Biomedical Research 11, 33-37.

Omoregie, R., Omokaro, E.U., Palmer, O., Ogefere, H.O., Egbeobauwaye, A., Adeghe, J.E., Osakue, S.I. \& Ihemeje V. (2009) Prevalence of anaemia among HIV patient in Benin City, Nigeria. Tanzanian Journal of Health Research 11, 1-4.

Philips, K.D. \& Maureen, G. (2002) Differentiation and treatment of anaemia in HIV disease. Journal of the Association of Nurses in AIDS Care 13, 46-72.

Stephenson, L.S., Latham, C., Kurz, K.M., Kinoti, S.N., Oduori, M.L. \& Crompton, D.W.T. (1985) Relationships of S. haematobium hookworm and malarial infections and metrifonate treatment on haemoglobin level in Kenyan school children. American Journal of Tropical Medicine and Hygine 34, 519-528.

Vuylsteke, P., Bertrand, C., Verhoef, G.E., Vandenberghe, P. (2004) Case of megaloblastic anaemia caused by intestinal taeniasis. Annals of Hematology 83, 487-488

Zelalem, M.T., Abebe, G. \& Mulu, A. (2008) Opportunistic and other parasitic infections in AIDS patients, HIV seropositive healthy carriers and HIV sero-negative individual in southwest, Ethiopia. East African Journal of Public Health. 5, 169-173. 